\title{
Identification of limiting climatic and geographical variables for the distribution of the tortoise Chelonoidis chilensis (Testudinidae): a baseline for conservation actions
}

Alejandro Ruete, Gerardo C Leynaud

Background. Just as for most other tortoise species, the once common Chaco tortoise, Chelonoidis chilensis (Testudinidae), is under constant threat across it distribution in Argentina, Bolivia and Paraguay. Despite initial qualitative description of the species distribution and further individual reports of new locations for the species, there is no description of the species distribution in probabilistic terms. With this work we aim to produce an updated predictive distribution map for $C$. chilensis to serve as a baseline management tool for directed strategic conservation planning.

Methods. We fitted a spatially expanded logistic regression model within the Bayesian framework that accounts for uncertainty on presence-only and generated pseudo-absence data into the parameter estimates. We contrast the results with reported data for the national networks of protected areas to assess the inclusion of the species in spatial conservation strategies.

Results. We obtained maps with predictions of the occurrence of the species and reported the model's uncertainty spatially. The model suggests that potential suitable habitats for the species are continuous across Argentina, West Paraguay and South Bolivia, considering the variables, the scale and the resolution used. The main limiting variables were temperature-related variables, and precipitation in the reproductive period.

Discussion. Given the alarming low density and coverage of protected areas over the distribution area of $C$. chilensis, the map produced provides a baseline to identify areas where directed strategic conservation management actions would be more efficient for this and other associated species. 
1 Identification of limiting climatic and geographical variables for the

2 distribution of the tortoise Chelonoidis chilensis (Testudinidae): a baseline for

\section{3 conservation actions}

5 Authors: Alejandro Ruete ${ }^{1 *}$, Gerardo C. Leynaud ${ }^{2}$

6 Affiliation:

$7 \quad{ }^{1}$ Department of Ecology, Swedish University of Agricultural Sciences (SLU). Uppsala, Sweden.

$8 \quad{ }^{2}$ Centro de Zoología Aplicada, Facultad de Ciencias Exactas Físicas y Naturales, and Instituto de

9 Diversidad y Ecología Animal (CONICET - UNC). Universidad Nacional de Córdoba. Córdoba,

10 Argentina.

11

12 *Corresponding author: alejandro.ruete@slu.se; +46-18-672453 


\section{ABSTRACT}

15 Background. Just as for most other tortoise species, the once common Chaco tortoise,

16 Chelonoidis chilensis (Testudinidae), is under constant threat across it distribution in Argentina,

17 Bolivia and Paraguay. Despite initial qualitative description of the species distribution and

18 further individual reports of new locations for the species, there is no description of the species

19 distribution in probabilistic terms. With this work we aim to produce an updated predictive

20 distribution map for C. chilensis to serve as a baseline management tool for directed strategic

21 conservation planning.

22 Methods. We fitted a spatially expanded logistic regression model within the Bayesian

23 framework that accounts for uncertainty on presence-only and generated pseudo-absence data

24 into the parameter estimates. We contrast the results with reported data for the national networks

25 of protected areas to assess the inclusion of the species in spatial conservation strategies.

26 Results. We obtained maps with predictions of the occurrence of the species and reported the

27 model's uncertainty spatially. The model suggests that potential suitable habitats for the species

28 are continuous across Argentina, West Paraguay and South Bolivia, considering the variables,

29 the scale and the resolution used. The main limiting variables were temperature-related variables, 30 and precipitation in the reproductive period.

31 Discussion. Given the alarming low density and coverage of protected areas over the distribution

32 area of $C$. chilensis, the map produced provides a baseline to identify areas where directed

33 strategic conservation management actions would be more efficient for this and other associated

34 species. 


\section{INTRODUCTION}

37 Globally, turtles and tortoises are the most threatened group of vertebrates, with over half of all

38 their species threatened with extinction (van Dijk, Stuart \& Rhodin, 2000; Turtle Conservation

39 Fund, 2002). Exploitation and unregulated trade are the primary causes for sharp declines in

40 many turtle species, with habitat loss and degradation also being major factors in widespread

41 declines (Gibbon et al., 2000; van Dijk, Stuart \& Rhodin, 2000; Turtle Conservation Fund,

42 2002). Therefore, without directed strategic conservation planning, a significant portion of turtle

43 diversity could be lost over the next century (Buhlmann et al., 2009).

44 The common Chaco tortoise, Chelonoidis chilensis (Testudinidae, Gray 1870), is mainly

45 found in Argentina, but also in Bolivia and Paraguay (Cei, 1993; Cabrera, 1998). Although we

46 still lack demographic evidence of population decline, C. chilensis is severely threatened by

47 habitat degradation, poaching and illegal trade (Chebez, 2009). Thus, persistent threats and

48 continuous habitat transformation lead to its categorization as Vulnerable by the IUCN (Tortoise

$49 \&$ Freshwater Turtle Specialist Group, 2010) and its inclusion in the Appendix II of CITES.

An updated and refined distribution map of the species is required to serve as baseline for

51 future conservation measures. Specifically, it is important to evaluate the contribution of the

52 protected area network to the conservation of $C$. chilensis. However, despite initial qualitative

53 and coarse descriptions of the species distribution (e.g. Waller, 1986; Buskirk, 1993; Richard,

54 1999) and further individual reports of new locations for the species (e.g. Cei, 1993; Gonzales,

55 Muñoz \& Cortéz, 2006; Fritz et al., 2012), there is no description of the distribution of the

56 species in probabilistic terms. Species distribution models (SDMs) are a way of linking species

57 occurrence data to environmental variables explaining and limiting the species distribution

58 (Cassini, 2011). SDMs can further provide a spatial depiction of probabilities of occurrence 
59 rather than deterministic presence-absence maps. Because of the lack of systematic surveys at a

60 national scale, the only data available for this species are presence-only records from museums

61 and other literature. Given the great uncertainty inherent to this kind of data, state of the art

62 Bayesian modelling techniques are required to account for this uncertainty and present it as part

63 of the resulting species distribution map (Lobo, Jiménez-Valverde \& Hortal, 2010).

With this work we aim to produce an updated predictive distribution map for Chelonoidis

chilensis, based on geographical and bioclimatic explanatory variables and accounting for data uncertainty, as a baseline management tool for the conservation of the species. We aim to i) gather as many records as possible for the species in Argentina, Paraguay and Bolivia; ii) develop a probabilistic species distribution model using presence-only data that accounts for data uncertainty and spatial autocorrelation of the explanatory variables; and iii) determine the inclusion of the species on protected areas by comparing model predictions to independent

71 presence-absence datasets for the protected areas.

\section{METHODS}

\section{Data collection}

In the current study the species is defined following Fritz et al. (2012), who concluded that 1973) are the same species (i.e. C. chilensis). C. chilensis is a burrow-nesting species, found on sandy soils in scrublands or dry forests in the ecoregions of Monte and Chaco (Fig. 1; Cei, 1993; confirmed observations of the Chaco tortoise dated 1950-2012 from the EMYSystem World

81 Turtle Database (http://emys.geo.orst.edu/), and from scientific literature (Waller, 1986; Buskirk, 
82 1993; Ergueta \& Morales, 1996; Cabrera, 1998; Ernst, 1998; Richard, 1999; Gonzales, Muñoz \&

83 Cortéz, 2006; Fritz et al., 2012). We merged all reported observations in a GIS vector layer using

84 QuantumGIS 1.8 (Quantum GIS Development Team, 2012). In case of overlap within $5 \mathrm{~km}$ we

85 kept only the latest observation to avoid duplicated reports, and oversampling in densely

86 populated areas. We also excluded three observations located close to Buenos Aires city because

87 based on previous descriptions of the species distribution they most likely belong to translocated 88 individuals. For a complete list of the 244 observations and corresponding sources, see Table S1

89 in Supporting Information. We arbitrarily defined the study area (Fig. 1) larger than the observed

90 species distribution to include surrounding areas where the species is known to be absent. We

91 excluded Chile from the study area because the Andean Mountain Range is a physical barrier the

92 species cannot pass (i.e. highest observation at 1200 m.a.s.l.; Richard, 1988).

93 We obtained geographic and bioclimatic data from raster layers with $5 \mathrm{~km}$ resolution

94 from two world databases (Hijmans et al., 2005; Hengl, 2009). The complete list of variables

95 included in the study is presented in Table S2. We did not included land-use variables in the

96 analysis because the data collected covers a wide temporal range (1950-2012), and the landscape

97 has changed dramatically over this time period.

99 Modelling the species distribution

100 We implemented a Bayesian spatially expanded logistic (BSEL) model (Casetti, 1997; Congdon,

101 2003) to obtain the probability of occurrence at non-visited locations. Non-visited locations were

102 randomly located with the same density as the observed locations $\left(\sim 0.0004 / \mathrm{km}^{2}\right)$. Given the

103 nature of presence-only data, predicted probabilities combine the probability of the species being

104 at the location, the probability of an observer being at the same location, and the probability of 
105 the observer finding the species (Lobo, Jiménez-Valverde \& Hortal, 2010). The Bayesian

106 approach allows us accounting for all three uncertainty sources on each observation, and

107 displaying the model's uncertainties spatially. We assume that occurrences at every non-visited

108 location $i$ are distributed according to a Bernoulli distribution $O b s_{i} \sim \operatorname{Bernoulli}\left(p_{i}^{*}\right)$, where $p_{i}^{*}$ is

109 an a priori probability distribution generated from confirmed observations (Fig. 1b). We

110 generated the a priori probability distribution as a quadratic density kernel raster layer using the

111 R package "splancs" (Rowlingson et al., 2013). By generating a prior distribution from the

112 observations, we assume that the entire study region has been sampled for the species with the

113 same intensity, which is a fair assumption given the map resolution and the time span of the

114 study.

115 We then modelled observations $O b s_{i}$ according to a logistic model, $O b s_{i} \sim \operatorname{Bernoulli}\left(p_{i}\right)$,

116 The spatially expanded model (Casetti, 1997; Congdon, 2003) assumes that the effect of an

117 explanatory variable on the response variable $p_{i}$ can vary among the observed locations. This

118 assumption is particularly convenient when fitting species distribution models along large

119 ranges, where the species can be locally adapted to e.g. temperature ranges (Turchin \& Hanski,

120 1997; Nilsson-Örtman et al., 2013). The model was fitted using JAGS 3.0 (Plummer, 2012)

121 through R (R Development Core Team, 2014). For further details on the modelling approach see 122 Appendix S1.

123 The final model presented (Table 1) is the result of a forward stepwise selection

124 procedure based on the deviance information criterion (DIC), an information-theoretic criterion

125 similar to Akaike's information criterion (a.k.a. AIC), that is appropriate for Bayesian

126 hierarchical modelling (Spiegelhalter et al., 2002). For further details on the selection procedure

127 and all tested variables see Appendix S1 and Table S2. 
Once the final model was obtained, we generated maps for the occurrence probability.

129 We predicted occurrence probabilities for regularly distributed locations with the same resolution

130 as the raster images for environmental variables (i.e. $5 \mathrm{~km}$ ). We generated raster layers for the

131 mode and for the length of the $95 \%$ credible interval $(95 \% \mathrm{CI})$. The length of the $95 \% \mathrm{CI}$ is a

132 measure of precision ranging from 0 (precise) to 1 (imprecise).

134 Model evaluation

135 We calculated the AUC index with the SDMtools package for R (VanDerWal et al., 2012),

136 contrasting predictions (Fig. 2a) against the a priori probability distribution (Fig. 1b). Then, we

137 contrasted model predictions with two independent datasets of observations of Chaco tortoises in

138 Argentinean and Bolivian protected areas (a similar dataset for Paraguay was not available). The

139 first data set is mainly based on park rangers reports, and includes 144 Argentinean protected

140 areas in the study area (Sistema de Información de Biodiversidad, SIB; Administración de

141 Parques Nacionales, 2012). The second data set was put together in the framework of a doctoral

142 thesis (Embert, 2007), and includes museum and field systematic collections for 38 Bolivian

143 protected areas in the study area. The species was reported as present in 14 Argentinean and 3

144 Bolivian protected areas (Table S3).

\section{RESULTS}

147 The final species distribution model obtained for Chelonoidis chilensis was mainly driven by 148 temperature-related variables, but also included water availability in the reproductive period (i.e.

149 precipitation in warmest quarter; Table 1). From this model we generated maps displaying the

150 probability of occurrence (Fig. 2a) and the model's uncertainty. The model suggests that 
151 potential suitable sites of the species are continuous across Argentina, West Paraguay and South

152 Bolivia, considering the variables, the scale and the resolution used. The model's predictions

153 generally overlap with published distribution maps for the species (Waller, 1986; Ernst, 1998;

154 Richard, 1999; Administración de Parques Nacionales, 2012; Fritz et al., 2012) and with the

155 ecoregions where the species has been described from (Fig. 1a). The model predictions' accuracy

156 is relatively high $(\mathrm{AUC}=0.92)$. The uncertainty of the model was generally low (i.e. $95 \% \mathrm{CI}$

157 length $<0.5$, Fig. $2 b$ ) and is lower in areas where the occurrence probability is close to either 0 or

1581 (Fig. S1). However, uncertainty is highest in areas with low density of observations (e.g.

159 Bolivia).

160 The model has very low omission error (i.e. false negatives). In Argentina, the model

161 predicts low occurrence probabilities $(p<0.5)$ for only one out of 14 protected area where the

162 species has been reported ( $\mathrm{p}=0.45$; Table S3.1). However, although the model predicted $p<0.3$

163 for all protected areas in Bolivia (Fig. S2, Table S3.2), there were confirmed observations in

164 three protected areas. Conversely, the commission error is high. That is, there is large

165 discrepancy between positive predictions and the validation dataset, indicating potential false

166 positives. Out of a total of 25 Argentinean protected areas where the model predicted $p \geq 0.5$ the

167 species was not reported in 12 of them.

168

169 DISCUSSION

170 The model predicts a large and continuous area where Chelonoidis chilensis may be found,

171 taking into account the selected variables, the scale of the study area and the resolution used. In

172 general terms, temperature-related variables constrain the latitudinal and altitudinal range of the

173 species, as it is expected for ectothermic species like amphibians and reptiles (Araújo, Thuiller \& 
174 Pearson, 2006). Even more, precipitation-related variables constrain its range longitudinally.

175 Altitude is certainly correlated to annual mean temperature, and this may be the reason why

176 altitude did not improve the model fit when added to the full model. In the same way, leaf area

177 index is expected to be highly correlated to precipitation in summer (i.e. the reproductive

178 season), a variable that explains the adaptation of the species to dry environments (Waller, 1986;

179 Buskirk, 1993; Ernst, 1998). However, correlation among variables per se was not a deterrent to

180 test for variables together in a model because the aim of a predictive model is to capture and

181 explain as much variability in the response variable as possible (Reichert \& Omlin, 1997).

183 Model uncertainty and usage of predictions

184 An honest display of model uncertainties is crucial to evaluate and validate model predictions.

185 We observed that higher uncertainty is expected on transition areas between high and low

186 estimated probabilities or on poorly sampled areas (Figs. 2b and S1). In general, probabilities

187 obtained for each pixel on the map have uncertainties associated to the observation events (Lobo,

188 Jiménez-Valverde \& Hortal, 2010), as well as to the model that generated those probabilities

189 (Congdon, 2003; Clark \& Gelfand, 2006). Model uncertainty maps complement the information

190 contained on point estimate predictions, and should be displayed as yet another SDM result.

191 Species distribution maps generated with low quality data (e.g. presence-only data) could be

192 dangerously misleading if not accompanied with the corresponding uncertainty map. Too high or

193 too widely spread uncertainty would also question the accuracy of the model, suggesting that

194 more observations or alternative explanatory variables should be considered in the study. Also,

195 uncertainty maps can be a valuable tool for designing field work efficiently. The researcher can 
196 then decide to focus future sampling effort either on areas with high uncertainty to validate the

197 model or on areas with high probabilities of occurrence and low error to sample more efficiently.

198 For many practical applications it is necessary to transform continuous maps to binary

199 presence-absence maps assuming a (more or less) objective detection threshold (Liu et al., 2005;

200 Jiménez-Valverde \& Lobo, 2007). It is the researcher's task to decide on which side of the

201 detection threshold he/she wants the most of the model's uncertainty. Liu et al. (2005) and

202 Jiménez-Valverde and Lobo (2007) previously discussed that a threshold $t=0.5$ is not always the

203 best option, although it is often used. We observed that our model predictions have the highest

204 uncertainty (widest 95\% CI range) on regions where predicted occurrence probabilities are close

205 to 0.5 (Fig. S1). Choosing $t=0.4$ would leave higher uncertainties on values interpreted as

206 presences. The opposite is also true for $t=0.6$.

There are a few considerations to take into account when comparing the model

208 predictions with the presence of the species on protected areas. First, it is important to consider

209 the bias present on the distribution of protected areas. For example, commission error (i.e. false

210 positive rate) is probably underestimated on the east of the species distribution (Espinal and

211 Pampas ecoregions, $<1 \%$ protected) if compared to the cover on the core distribution area

212 (Monte and Chaco ecoregions, 3.7\% protected)(Chebez, 2009) because of a heavily unbalanced

213 distribution of protected areas (Fig. S2). Second, there are no data on the probability of detection

214 or in the completeness of observation reports within the protected areas. Chelonidis chilensis is

215 declared a "species of interest" by the National Parks Administration Office, requiring from its

216 entire field staff to report observations of the species to the National Biodiversity Information

217 System (Administración de Parques Nacionales, 2012). However, this is not necessarily the case

218 for provincial, municipal or private protected areas. Therefore, the discrepancy between high 
219 predicted probabilities of occurrence with low uncertainty on protected areas where the species

220 was not reported could be simply due to lack of reports or local extinction instead of model

221 commission error.

\section{Implications for conservation in protected areas}

224 An important aspect for the conservation of C. chilensis that emerges from this study is the low 225 density and total area of protected areas within the distribution of the species. Only $3.7 \%$ of

226 Monte and Chaco ecoregions are under some form of protection ("Secretaria de Ambiente y

227 Desarrollo Sustentable"). This value is far from the Aichi Biodiversity Target 11: 17\% of

228 terrestrial areas $[\ldots]$ are conserved through $[\ldots]$ systems of protected areas and other effective

229 area-based conservation measures (Convention on Biological Diversity, 2010). The current

230 situation is particularly alarming because of the continuous expansion of the agricultural

231 activities on these ecosystems (Chebez, 2009; Grau et al., 2014).

232 At a smaller scale than the one used on this study it is likely to find greater heterogeneity 233 and fragmentation of suitable habitats. The probability of occurrence of the species is likely to be

234 much lower in some sites after considering the effect of local variables describing the species

235 microhabitat (e.g. availability of favorable nesting sites), barriers to dispersal, human impact and

236 biotic interactions. For example, despite high and homogenous probabilities of occurrence

237 predicted for Sierra de las Quijadas National Park (which emblem depicts a Chaco tortoise), the

238 populations in the park are confined to restricted areas (personal observation). This local

239 heterogeneity is likely due to the wide variability in habitat types and geographic accidents as

240 well as due to the pressure of uncontained grassing activity by neighbor's cattle. Conversely, in 
241 Santiago del Estero Province (at the core of the species distribution) the rate of extraction from

242 unprotected areas does not seem to have decline over time (Prado et al., 2012).

This study does not aim to identify healthy populations but to guide the search for them.

244 Also, the predictive maps produced provide a baseline to identify areas where directed strategic

245 conservation management actions (e.g. creation or expansion of protected areas) would be more

246 efficient for this and other associated species. However, before new protected areas or

247 management plans could be delineated, more research is required to better understand what

248 variables drive local habitat selection within areas where the species is expected to be present.

\section{ACKNOWLEDMENTS}

251

252

253

254

255

256

257

258

259

260

261

262

We thank two reviewers and the editor for valuable comments on the manuscript.

\section{REFERENCES}

Administración de Parques Nacionales 2012.Sistema de información de biodiversidad. Available at http://www.sib.gov.ar/busqueda.php?qry=Chelonoidis\&qrydo.x=-1067\&qrydo.y=145

Araújo MB., Thuiller W., Pearson RG. 2006. Climate warming and the decline of amphibians and reptiles in Europe. Journal of Biogeography 33:1712-1728.

Buhlmann KA., Akre TSB., Iverson JB., Karapatakis D., Mittermeier RA., Georges A., Rhodin AGJ., van Dijk PP., Gibbons JW. 2009. A global analysis of tortoise and freshwater turtle distributions with identification of priority conservation areas. Chelonian Conservation and Biology 8:116-149. 
263 Buskirk JR. 1993. Distribution, status and biology of the tortoise, Geochelone chilensis, in Río 264 Negro Province, Argentina. Studies on Neotropical Fauna and Environment 28:233-249.

265 Cabrera M. 1998. Las tortugas continentales de Sudamérica austral. Argentina: Consejo

266 Nacional de Investigaciones Científicas y Técnicas.

267 Casetti E. 1997. The expansion method, mathematical modeling, and spatial econometrics. 268 International Regional Science Review 20:9-33.

269 Cassini MH. 2011. Ecological principles of species distribution models: the habitat matching $270 \quad$ rule. Journal of Biogeography 38:2057-2065.

271 Cei JM. 1993. Reptiles del noroeste, nordeste y este de Argentina. Herpetofauna de las Selvas 272 Subtropicales, Puna y Pampas. Torino: Museo Regionale di Scienze Naturali.

273 Chebez J. 2009. Los que se van: Fauna Argentina amenazada. Argentina: Albatros.

274 Clark JS., Gelfand A. 2006. Hierarchical Modelling for the Environmental Sciences: Statistical 275 Methods and Applications. Oxford University Press, USA.

276 Congdon P. 2003. Applied Bayesian modelling. West Sussex, England: John Wiley and Sons.

277 Convention on Biological Diversity 2010. Decision X/2: the strategic plan for biodiversity 20112782020 and the Aichi biodiversity targets.

van Dijk PP., Stuart BL., Rhodin AGJ. 2000. Asian Turtle Trade: Proceedings of a Workshop on 280 Conservation and Trade of Freshwater Turtles and Tortoises in Asia. Chelonian Research $281 \quad$ Monographs 2:1-4.

282 Embert D. 2007. Distribution, diversity and conservation status of Bolivian reptiles. Doctoral 283 Thesis Thesis. Bonn: Boon University.

284 Ergueta PS., Morales CB de. 1996. Libro rojo de los vertebrados de Bolivia. La Paz, Bolivia: 285 Asociación para la Biología de la Conservación - Bolivia. 
286 287 288 289

Ernst CH. 1998. Geochelone chilensis. Catalogue of American Amphibians and Reptiles 668:14.

Fritz U., Alcalde L., Vargas-Ramírez M., Goode EV., Fabius-Turoblin DU., Praschag P. 2012. Northern genetic richness and southern purity, but just one species in the Chelonoidis chilensis complex. Zoologica Scripta 41:220-232.

Gibbon JW., Scott DE., Ryan TJ., Buhlmann KA., Tuberville TD., Metts BS., Greene JL., Mills T., Leiden Y., Poppy S., Winne CT. 2000. The global decline of reptiles, déjà vu amphibians. BioScience 50:653.

Gonzales L., Muñoz A., Cortéz E. 2006. Primer reporte sobre la herpetofauna de la reserva natural "El Corbalán”, Tarija, Bolivia. Kempffiana 2:72-94.

Grau HR., Torres R., Gasparri NI., Blendinger PG., Marinaro S., Macchi L. 2014. Natural grasslands in the Chaco. A neglected ecosystem under threat by agriculture expansion and forest-oriented conservation policies. Journal of Arid Environments.

Hengl T. 2009. A Practical Guide to Geostatistical Mapping. Amterdam, The Netherlands: University of Amsterdam.

Hijmans RJ., Cameron SE., Parra JL., Jones PG., Jarvis A. 2005. Very high resolution interpolated climate surfaces for global land areas. International Journal of Climatology 25:1965-1978.

Jiménez-Valverde A., Lobo JM. 2007. Threshold criteria for conversion of probability of species presence to either-or presence-absence. Acta Oecologica 31:361-369.

Liu C., Berry PM., Dawson TP., Pearson RG. 2005. Selecting thresholds of occurrence in the prediction of species distributions. Ecography 28:385-393. 
308 Lobo JM., Jiménez-Valverde A., Hortal J. 2010. The uncertain nature of absences and their 309 importance in species distribution modelling. Ecography 33:103-114.

310 Nilsson-Örtman V., Stoks R., De Block M., Johansson H., Johansson F. 2013. Latitudinally

311 structured variation in the temperature dependence of damselfly growth rates. Ecology $312 \quad$ Letters 16:64-71.

313 Plummer M. 2012. JAGS: A program for analysis of Bayesian graphical models using Gibbs 314 sampling.

315 Prado WS., Waller T., Albareda DA., Cabrera MR., Etchepare E., Giraudo AR., González

316 Carman V., Prosdocimi L., Richard E. 2012. Categorización del estado de conservación 317 de las tortugas de la República Argentina. Cuadernos de herpetología 26:375-387.

318 Quantum GIS Development Team 2012. Quantum GIS Geographic Information System. Open 319 Source Geospatial Foundation Project.

320 R Development Core Team 2014. R: a language and environment for statistical computing.

321 Vienna, Austria: R Foundation for Statistical Computing.

322 Reichert P., Omlin M. 1997. On the usefulness of overparameterized ecological models.

$323 \quad$ Ecological Modelling 95:289-299.

324 Richard E. 1988. Las Yataché (Chelonoidis donosobarrosis: Chelonii, Testudine) de la región del 325 Nevado (Mendoza, Argentina). Apuntes sobre la hitoria natural. Amphibia y Reptilia $326 \quad 1: 79-92$.

327 Richard E. 1999. Tortugas de las regiones aridas de Argentina. Buenos Aires Argentina: $328 \quad$ L.O.L.A.

329 Rowlingson B., Diggle P., Bivand R., Petris G., Eglen S. 2013. splancs: Spatial and space-time $330 \quad$ point pattern analysis. 
331 Secretaria de Ambiente y Desarrollo Sustentable. Available at http://www.ambiente.gov.ar/default.asp?IdArticulo=3955 (accessed September 9, 2012).

333 Spiegelhalter DJ., Best NG., Carlin BP., van der Linde A. 2002. Bayesian measures of model complexity and fit. Journal of the Royal Statistical Society. Series B (Statistical Methodology) 64:583-639.

338 Turchin P., Hanski I. 1997. An empirically based model for latitudinal gradient in vole population dynamics. The American Naturalist 149:842-874.

Tortoise \& Freshwater Turtle Specialist Group. 2010.Chelonoidis chilensis. Available at http://www.iucnredlist.org/apps/redlist/details/9007/0 (accessed December 21, 2010).

Turtle Conservation Fund 2002. A global action plan for conservation of tortoises and processing data associated with species distribution modelling exercises.

345 Waller T. 1986. Distribucion, habitat y registro de localidades para Geochelone chilensis (Gray, 1870) (Syn donosobarrosi, petersi) (Testudines, Testudinidae). Amphibia \& Reptilia 1:10. 
349 Table 1: Explanatory variables included in the final model. Deviance Information Criterion 350 (DIC) are calculated stepwise from the null model (Table S2). Estimates of the effect parameters $351(\delta)$ are extracted from the final model.

352

353

354

355

356

357

358

359

360

361

362

Mean annual temperature

$\begin{array}{llll}930.4 & 0.56 & -4.68 & 5.14\end{array}$

Max. temperature of warmest month

$\begin{array}{llll}869.4 & 1.61 & -2.05 & 5.86\end{array}$

Temperature annual range

$\begin{array}{llll}853.7 & 0.03 & -2.25 & 2.12\end{array}$

Precipitation of warmest quarter

$\begin{array}{llll}824.5 & -1.57 & -2.35 & -0.80\end{array}$

363

364

a: mode of the effect parameter.

365

366 

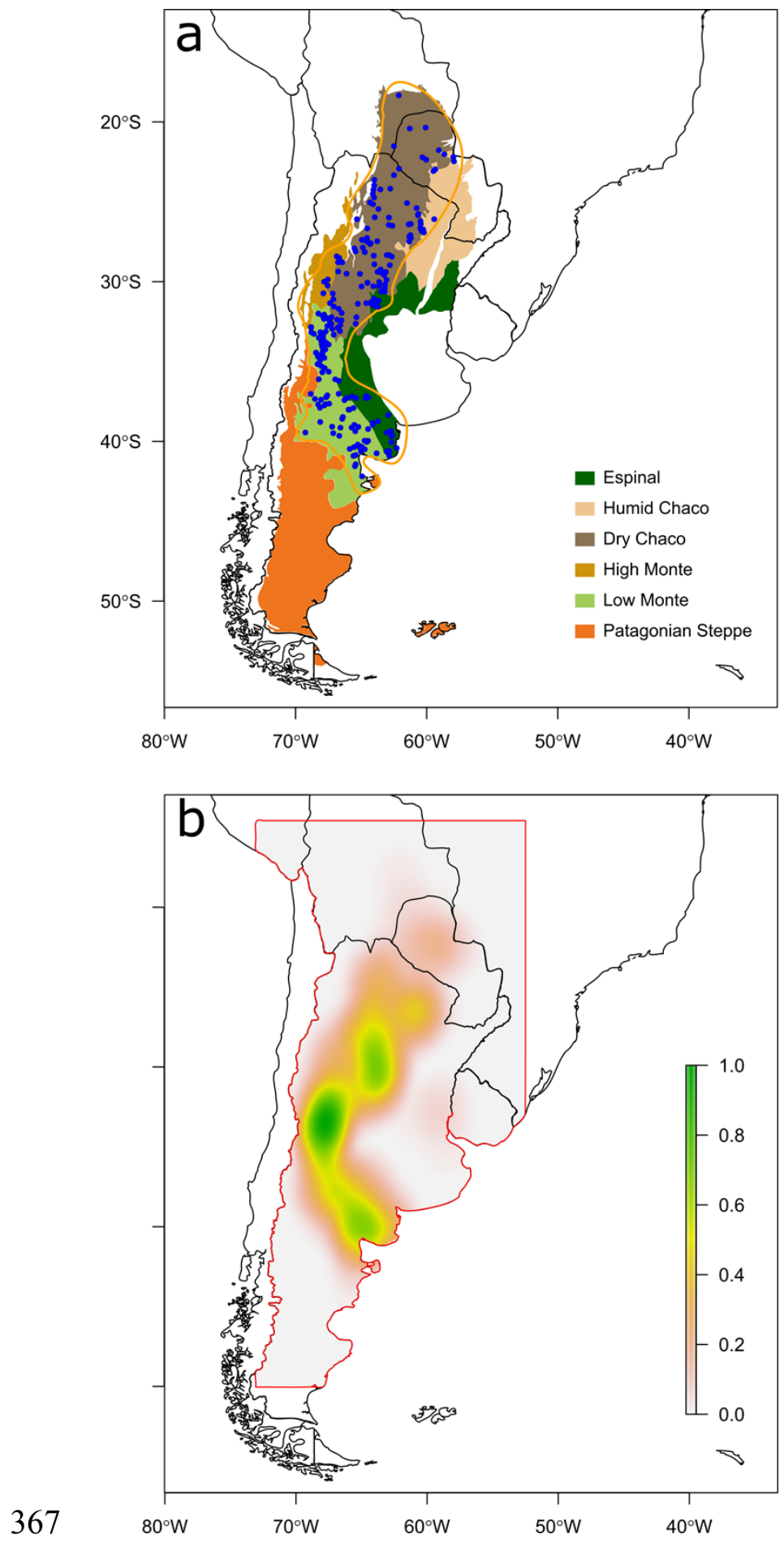

368 Figure 1: Map of austral South America, showing a) sites of confirmed observations of

369 Chelonoidis chilensis (blue dots) and ecoregions where the species has been observed (coloured 
370 polygons); b) a priori probability distribution of observations (colour scale) estimated from

371 observation densities.

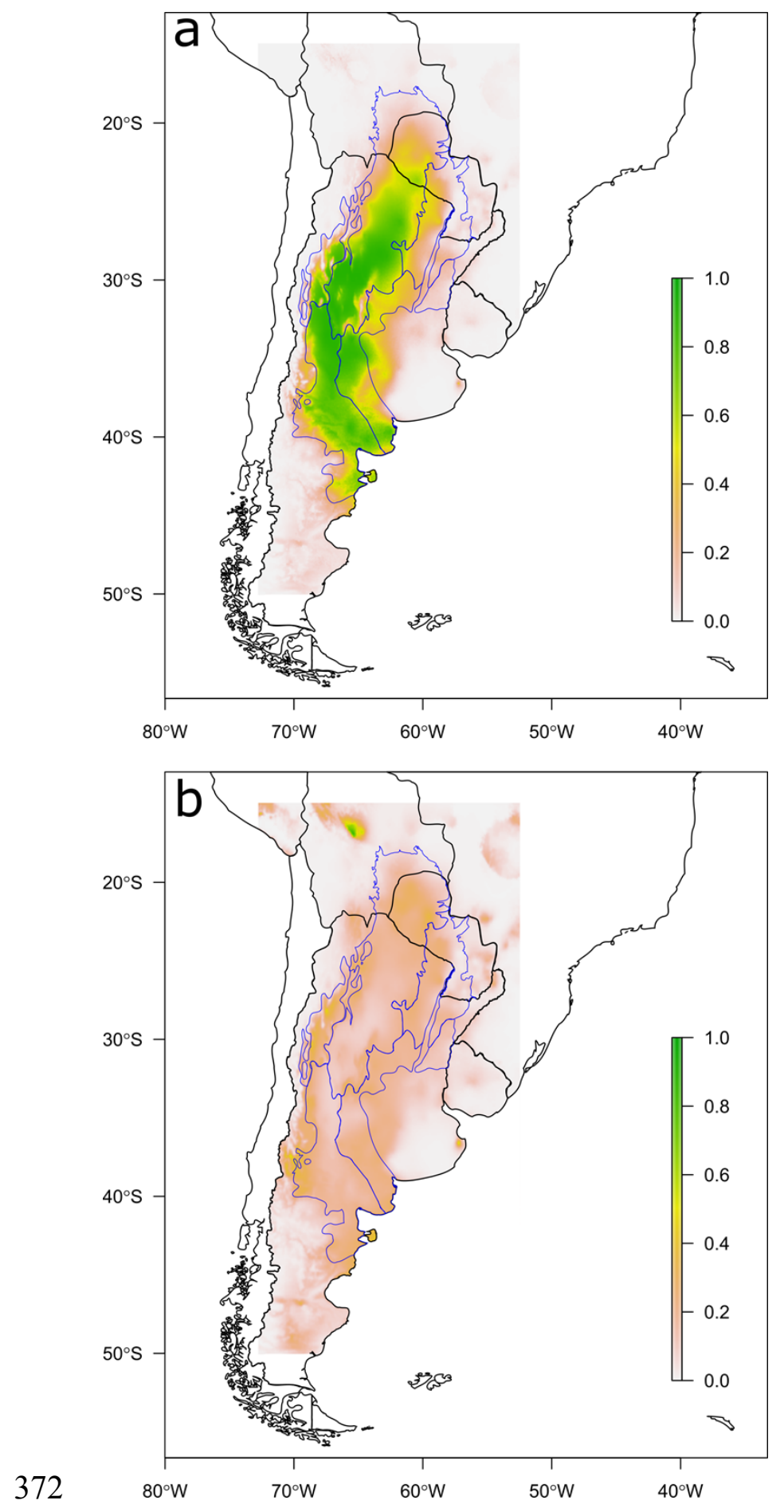


373 Figure 2: Maps showing a) mode and b) length of the $95 \%$ Credible Interval (CI) of probabilities

374 of occurrence generated with the Bayesian Spatially Expanded Logistic model (BSEL). Blue

375 lines show ecoregions delimitation for comparison with Figure 1a. 


\section{1}

Observations and a priori probability distribution of Chelonoidis chilensis.

Figure 1: Maps of observations and a priori probability distribution of Chelonoidis

chilensis. Map of austral South America, showing a) sites of confirmed observations of Chelonoidis chilensis (blue dots) and ecoregions where the species has been observed (coloured polygons); b) a priori probability distribution of observations (colour scale) estimated from observation densities. 

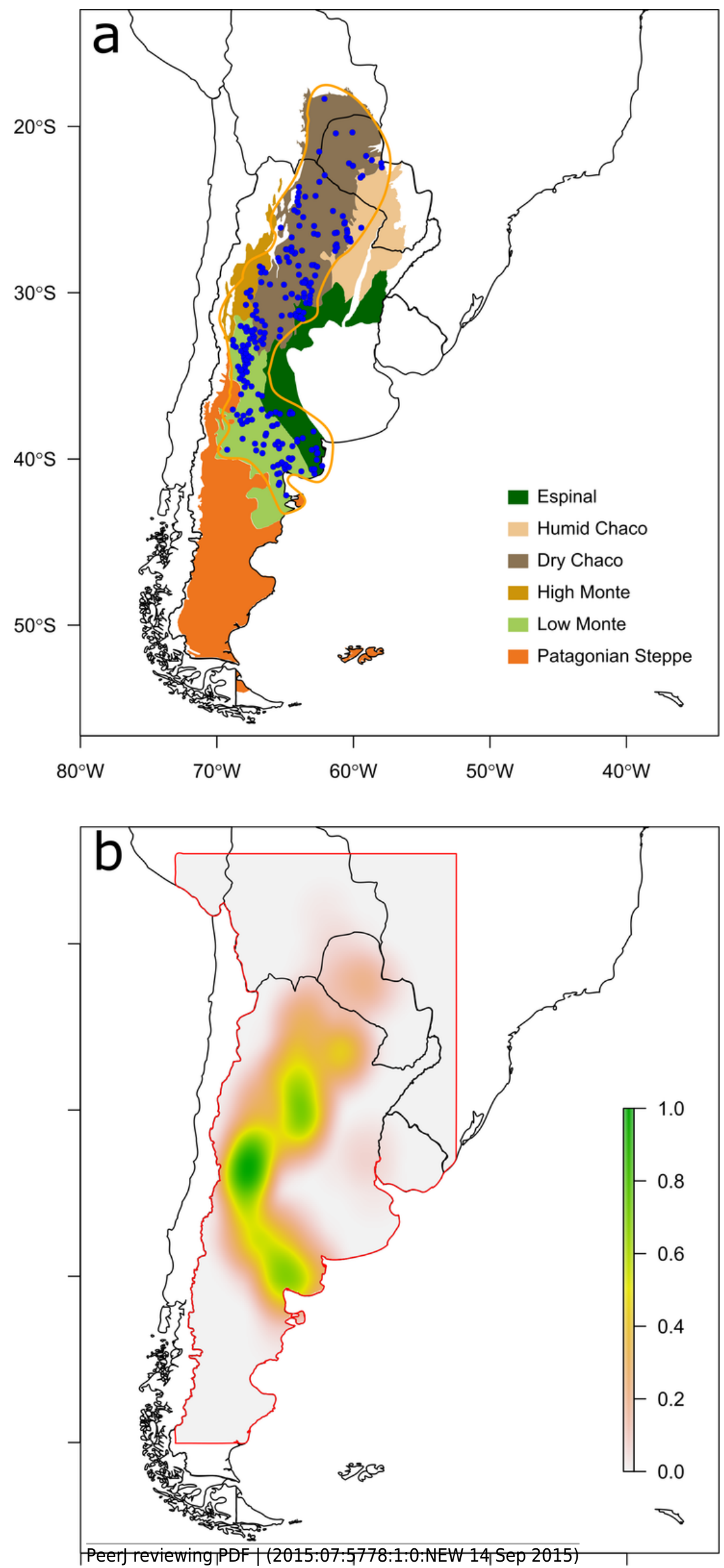
$80^{\circ} \mathrm{W}$ $70^{\circ} \mathrm{W}$ $50^{\circ} \mathrm{W}$ $40^{\circ} \mathrm{W}$ 
2

Predictions of the species distribution model.

Figure 2: Predictions of the species distribution model. Maps showing a) mode and b) length of the $95 \%$ Credible Interval $(\mathrm{Cl})$ of probabilities of occurrence generated with the Bayesian Spatially Expanded Logistic model (BSEL). Blue lines show ecoregions delimitation for comparison with Figure 1a. 

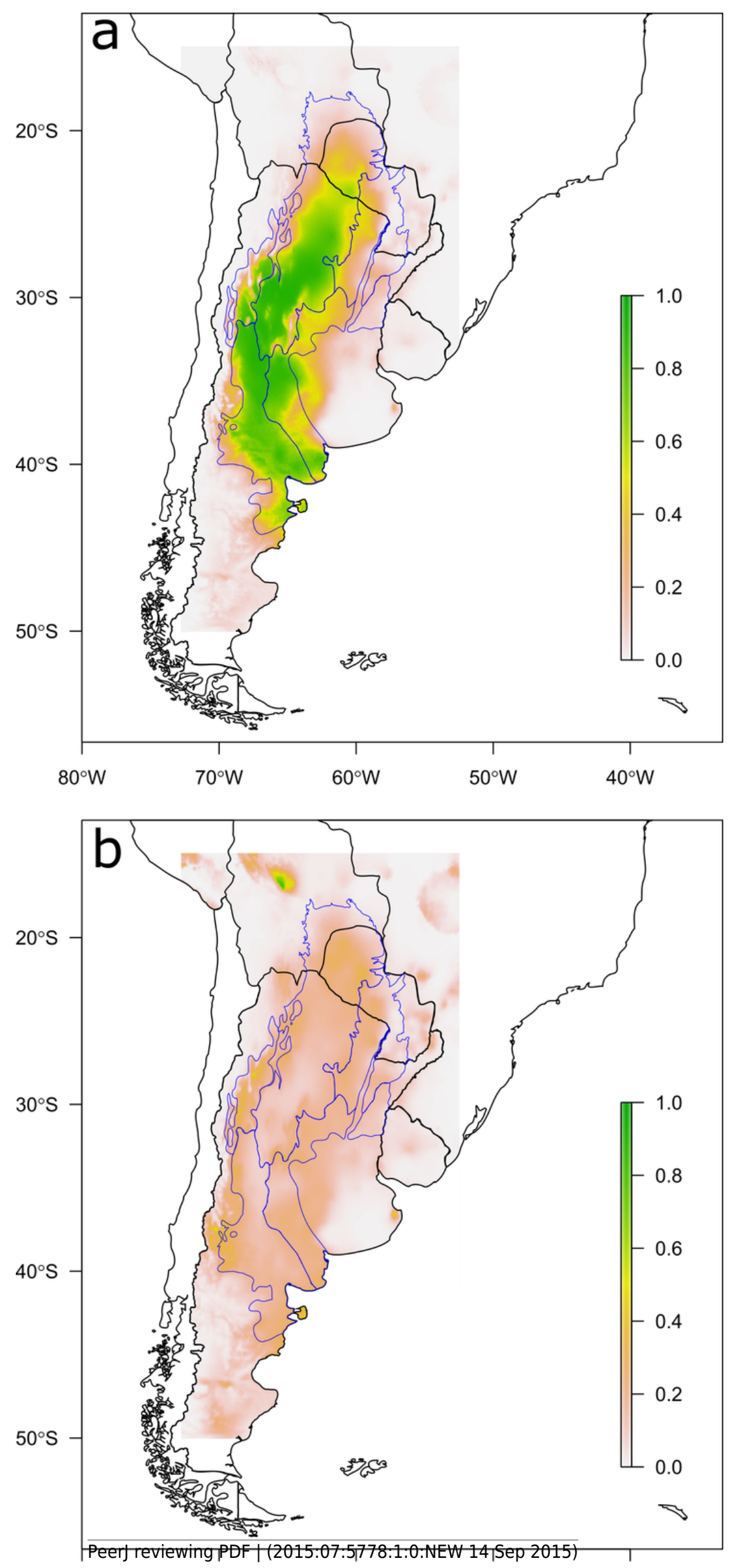